\title{
Factors Associated with Smoking Cessation and Risk of Smoking Initiation in Bulgarian Youth
}

\author{
Milena D. Anatchkova, Colleen A. Redding, Joseph S. Rossi \\ University of Rhode Island, Cancer Prevention Research Center
}

\begin{abstract}
The goal of this project was to explore the factors associated with smoking behavior among Bulgarian adolescents. A sample recruited from 12 high schools in Bulgaria $(\mathrm{N}=673$, mean age $=16.52,65 \%$ female), was used for the analyses in this paper. A series of logistic regressions were performed to explore the factors associated with smoking cessation and increased risk of smoking initiation. Based on self-reported smoking status participants completed different sets of questionnaires and were included in separate models exploring smoking cessation and increased risk of smoking initiation. Variables consistently associated with smoking like stress, coping strategies, peer influence, family influence, exposure to tobacco related marketing were included as predictor variables in both models. In addition each of the two models included the relevant constructs of decisional balance and temptations from the Transtheoretical Model (TTM). The final logistic model differentiating smokers/ex-smokers included age, parental smoking status, Temptation to smoke, and support for smoking bans in public places as variables, correctly classifying $82.3 \%$ of the sample. The final model among nonsmokers differentiating higher risk/lower risk of smoking initiation included the strength of the belief that smoking is harmful, Temptations to try smoking, Pros of being smoke-free, and support for smoking bans in public places, correctly classifying $72.7 \%$ of the sample. These results provide better understanding of the factors associated with smoking behavior in Bulgarian adolescents that can guide the development of smoking cessation and prevention programs for this population.
\end{abstract}

(C) 2006 Californian Journal of Health Promotion. All rights reserved.

Keywords: smoking cessation, smoking prevention, transtheoretical model, adolescent smoking

Percentages of smokers in Bulgaria have reached alarmingly high levels among men (49.2\%), adolescents (24\% for males and $31 \%$ females) and even health professionals $(52.3 \%)$ (Corrao et al., 2000). According to other sources these figures are even higher, reaching $61.1 \%$ smoking prevalence in the male population (Uitenbroek, 1996) and the trend is for further increase. At the same time the mortality rate for the population shows a steady increase in the last decade with invariably increasing numbers in the leading cause of death - cardiovascular diseases (Ginter, 1997). Research indicates that smoking initiation for adult users usually occurs during adolescent years (Fiore, 1992) and smoking is unlikely to occur if it is not started during adolescence (US Surgeon General, 1994). It is estimated that around $50 \%$ of teenage youth that initiate smoking remain addicted for 16 to
20 years (Najem, Batuman, Smith, \& Feuerman, 1997).

Some efforts have been made to control tobacco products in Bulgaria. Advertising and sales to minors are officially banned, but the lack of appropriate enforcement minimizes the effectiveness of this effort. Smoking is prohibited in educational and health facilities, government buildings and public transportation but it is allowed and heavily practiced in all other public places (restaurants, bars, pubs, clubs), which are often visited by youth and have become a powerful channel for promotional activities for the tobacco companies (World Health Organization, 1997). As a large producer of tobacco, Bulgaria maintains very low prices of domestic cigarettes $(\$ 0.40$ average cost per pack at the time of the study), which has 
more than $90 \%$ of market share. This low cost facilitates easy access to tobacco products.

Even though in recent years changes in Bulgarian tobacco related policy have been introduced (WHO, 2002; Ministry of Health, 2002), support for health promotion activities, smoking prevention and educational activities in the last decade remains particularly weak (Balabanova, Bobak \& McKee, 1998). The reports on some prevention strategies most often describe some pilot programs and prevention efforts (Anguelov et al., 1999), and short term campaigns such as "Quit and Win" (Tulevski \& Vasilevski, 2000) and theme competitions "No to cigarettes" (Kotarov, 2002), performed as a part of an international campaign.

This context does not provide many anti-tobacco messages, placing adolescents at high risk for smoking initiation and accompanying health hazards and underscoring the need for good smoking prevention and cessation programs. Public health officials in the country face two immediate tasks - one is to develop good prevention programs to stop further increases in the smoking rates among this segment of the population and the other is to develop programs that will help current smokers to quit. An important prerequisite for the successful development of such programs is good understanding of the factors that influence smoking initiation and maintenance in adolescence. While this need has given rise to a substantial body of research into the psychosocial correlates of smoking in the US (US Surgeon General, 2000), similar research in Bulgaria is virtually missing.

The goal of the study is to partially fill this gap by exploring the factors that contribute to successful smoking cessation among adolescents in Bulgaria. A cross-sectional study was designed to assess the factors traditionally associated with smoking such as stress (Koval, Pederson, Mills, McGrady, \& Carvajal, 2000; SiQuira, Diab, Bodian, \& Rolnitzky, 2000; Weinrich, Hardin, Valois, \& Gleaton, 1996; Wills, 1986), coping strategies (McCubin, Needle, \& Wilson, 1985; Siquierra et al., 2000; Vollrath, M., 1998), self esteem (Glendinning \&
Inglis, 1999; Jackson \& Henricksen, 1997; Kawabata, Shimai \& Nishoka, 1998;), peer influence (Griesler \& Kandel, 1998; Jackson, 1997; Urberg, Cheng, \& Shyu, 1991), family influence (Piko, 2000; Proescholdbell, Chassin, \& MacKinnon, 2000; Wang, Fitzhugh, Westerfield, \& Eddy, 1995) and tobacco related marketing (Unger, Cruz, Schuster, Flora, \& Johnson, 2001). The Transtheoretical model (TTM) (Prochaska \& DiClemente, 1983) framework was used to evaluate the readiness of participants to either quit smoking or start smoking using the stages of change algorithm. Furthermore, cognitive appraisals of the costs and benefits of smoking were assessed through the TTM decisional balance construct and level of self-efficacy was assessed through the TTM temptation construct. It was hypothesized that TTM constructs would be good predictors of being an ex-smoker (compared to a smoker) and being committed to remain smoke-free (compared to not), along with levels of stress and peer and family influences.

\section{Methods}

\section{Procedure}

The sample for this project consisted of students in the last grades of high school (15-19 years old) recruited in 12 randomly selected high schools of the two largest cities in Bulgaria (Sofia and Plovdiv). The University of Rhode Island Institutional Review Board and the Bulgarian Ministry of Education approved all data collection protocols. The schools were selected to represent the major school types in the country (with general, technical and humanitarian profiles). The principals of 14 schools were approached with a request for participation. Two of the schools declined due to the approaching end of the semester and in one of the schools the students had recently participated in a different study exploring risky behaviors. After permission was obtained from the principal of a school further arrangements were made with a teacher for data collection. The investigator administered the survey materials. All participants were presented an assent or consent form prior to their participation and were offered a small incentive for their time (a set of pens and a small organizer). The survey materials were distributed along with a white 
envelope in which participants sealed and returned their anonymous answers. None of the students declined participation and only 5 empty cards were returned.

\section{Measures}

The full battery consisted of a number of measures translated for the first time into Bulgarian and used with a Bulgarian sample. The majority of the measures were TTM constructs. In addition some stress and family influence measures, as well as items related to tobacco related marketing and peer influence were included to answer specific research questions. All participants were presented with the full battery of instruments. The first part, including demographics and stress questions, was the same for all participants. After that, depending on their smoking status participants were guided through one skip pattern to one of two different sets of items for smokers or for nonsmokers. Only the measures relevant to the current analyses will be presented here.

Smoking status definition questions: Two questions were used to determine the smoking status of participants. The first divided subjects in ever smokers and never smokers. The second differentiated between never smokers, regular smokers, experimental smokers and quitters. Depending on his or her smoking status each participant received a battery of TTM measures. The regular smokers and the quitters were guided to a set of questions related to their experiences with smoking. Never smokers and participants who identified minimal experimental behavior (e.g., a few puffs in a lifetime) were guided to a set of questions focusing on their attitudes towards smoking and assessing their potential risk for smoking initiation. The following measures were included in the questionnaire.

Demographic section: This set of questions assessed age, gender, ethnicity, grade level, type of school, level of parents' education and future plans for all students. It also included the date of survey completion.

Perceived Stress Scale: A 14-item scale measured the degree to which situations in one's life are appraised as stressful (Cohen, Kamarck, Mermelstein, 1983).

RISCI: The Rhode Island Stress and Coping inventory was a 10 item scale assessing physical symptoms and ways of coping with stress (Fava, Ruggiero, \& Grimley, 1998).

Family influences: The amount of family support for nonsmoking was assessed by this four-item scale (Redding, Rossi et al., 1998, 1999).

Stages of stress management for adolescents: This algorithm asked about the consistency and efficacy of stress management and the time devoted to active stress management per day (Mauriello et al., 2006).

Media exposure to smoking messages and opinions about smoking: A set of questions assessed participants' exposure to media images related to smoking (ads and anti-smoking messages) and some attitudes towards smoking (questions were adapted from the WHO/CDC GYTS).

Stages of change algorithms for smoking cessation and acquisition: A six-item scale assessing stages of readiness to quit smoking (Pallonen et al., 1998; Plummer et al., 2001) was administered to participants who had experience with smoking. A new staging scale for smoking acquisition (6 items) measuring participants' determination to stay smoke-free and hence their risk of becoming a smoker (Anatchkova et al., 2002) was used with non-smokers.

Decisional balance scales: The two decisional balance scales contain equal numbers of pros and cons either of smoking (Plummer et al., 2001) or of being smoke-free (Anatchkova et al., 2001). The scales measure the importance of each statement in the decision to quit smoking among smokers or the decision to stay away from cigarettes among nonsmokers. The existing English language scales have demonstrated three-factor models with good psychometric properties. The coefficient alphas in US teens were .79 for the Social Pros Scale, .87 for the Coping Pros scale and .88 for the Cons scale for 
smokers. The corresponding coefficients for nonsmokers were respectively $.68, .79$ and .86 (Plummer et al., 2001). Comparable Alphas were obtained in this Bulgarian adolescent sample (Anatchkova et al., 2006). Psychometric validation of these scales for Bulgarian adolescents have been presented elsewhere (Anatchkova, Redding, \& Rossi, 2006, in press).

Temptation scales: These two scales measured individual's temptation to smoke (among ever smokers) or to try smoking (among never smokers) in a range of challenging situations (Plummer et al., 2001). As with the decisional balance scales new item pools were created for the Bulgarian sample and the resulting measures were compared with the English language measures. Plummer et al. (2001) reported on a four factor hierarchical structure for Temptation among US teen smokers, namely Habit Strength, Positive Social, Negative Affect, and Weight Control. All factors demonstrated good Cronbach's alphas, ranging form .72 to .81 , and good factor loadings. For US teen nonsmokers, a five-factor hierarchical model including the four factors for smokers plus a new factor labeled Curiosity was obtained (Plummer et al., 2001). Alpha coefficients ranged from .66 to .85 . Comparable structures and Alphas were found in Bulgarian adolescents (Anatchkova et al., 2006, in press).

\section{Analytic Plan}

Two research questions were addressed in the current study. The first was to explore the factors that differentiate smokers in later postaction stages of change (Action and Maintenance) from those in earlier preaction stages of change (Precontemplation, Contemplation, and Preparation). For this purpose only participants that were classified as either smokers or ex-smokers were selected and included in the first logistic regression model. Participants were pooled into two groups - one including those in preaction stages and the other including those in post-action stages. This grouping variable (Current smoker vs. Exsmokers) was the outcome variable in a series of logistic regression analyses.
The second aim of this study was to identify the factors associated with elevated risk of smoking initiation among non-smokers and to examine their ability to discriminate between the two groups. Only participants that identified themselves as non-smokers were included in this model. The stages of readiness to make a commitment to stay smoke-free were used to identify participants at higher risk of smoking initiation. Students in the Precontemplation, Contemplation, and Preparation stages of readiness to commit to staying smoke-free were combined into one group labeled "elevated risk" and participants in Action and Maintenance were collapsed into a low-risk group. Thus, the outcome variable was dichotomized (elevated risk $=1$ ) and another series of logistic regression analyses were performed.

\section{Results}

\section{Participants}

The study procedure resulted in the data collected from 673 participating students $(64.8 \%$ female, 16.5 years mean age). Of these 276 identified themselves as smokers or ex-smokers and were included in the models evaluating factors associated with smoking cessation. Three hundred sixty nine participants identified themselves as nonsmokers and were included in the model exploring factors associated with risk of smoking initiation. The smoking status could not be determined for 28 of the participants due to missing data and these cases were excluded from further analysis.

The sub-sample of smokers and ex-smokers was predominantly female $(69.5 \%)$, with a mean age of 16.7 years. Ninety six percent of the sample self identified as Bulgarian and the rest indicated some other ethnic, national or religious group. Most of the students were planning to attend college in the country $(61.8 \%)$ or abroad (18.1\%) and had an average GPA of 5.08 on a six point rating scale (equivalent of $\mathrm{B}$ ). The stages of readiness to quit distribution was as follows: $129(47.6 \%)$ in precontemplation, 82 $(30.3 \%)$ in contemplation, $3(1.1 \%)$ in preparation, $30(11.1 \%)$ in action and 27 $(10.0 \%)$ in Maintenance and five people could not be staged. Since the number of participants in preparation was very low a combined stage group of $\mathrm{C} / \mathrm{PR}$ was created. When the stages 
were pooled into a preaction and postaction group $214(79.0 \%)$ were classified in preaction and $57(21.0 \%)$ in postaction.

The sub-sample of nonsmokers had a mean age of 17 years, was predominantly female $(61.4 \%)$ and $97.1 \%$ identified their ethnicity as Bulgarian. The majority of the sample $(58.6 \%)$ reported excellent performance in the last semester of school. Most of the students planned to attend college: $60.9 \%$ planned to attend college in the country and $23.2 \%$ were planning to continue their education abroad.

Logistic regression results: Smoking cessation Initially univariate tests were performed (t-tests and chi-square tests) on all variables of interest in order to select the variables for inclusion in the model. Variables with $\mathrm{p}$ levels lower than .20 were retained for inclusion. Based on the univariate results nine of the original variables were retained for further analysis: age, gender, GPA, parents' smoking status, number of friends who smoke, attitudes towards bans on smoking, coping pros, temptations and stages of effective stress management. The correlations among these variables were examined but no multicollinearity was observed.

The analysis proceeded with a logistic regression model containing all nine variables (see Table 1) and the outcome variable (smoker $=0$, quitter $=1)$.

Table 1

Initial logistic regression model for smokers/ex-smokers*

\begin{tabular}{|l|r|r|r|r|r|r|r|c|}
\hline & \multicolumn{1}{|c|}{ B } & \multicolumn{1}{c|}{ S.E. } & \multicolumn{1}{c|}{ Wald } & df & \multicolumn{1}{c|}{ p } & \multicolumn{2}{c|}{ OR } & \multicolumn{2}{|c|}{ 95.0\% C.I. for OR } \\
\hline & & & & & & & Lower & Upper \\
\hline Age & -.451 & .193 & 5.442 & 1 & .020 & .64 & .44 & .93 \\
\hline GPA & .015 & .260 & .003 & 1 & .954 & 1.02 & .61 & 1.69 \\
\hline How many close friends smoke & -.243 & .273 & .791 & 1 & .374 & .79 & .46 & 1.34 \\
\hline Parents' smoking & & & & & & & & \\
\hline No (Reference) & & & 8.397 & 3 & .038 & & & \\
\hline \multicolumn{1}{|c|}{ Only father } & -.487 & .564 & .745 & 1 & .388 & .62 & .20 & 1.86 \\
\hline \multicolumn{1}{|c|}{ Only mother } & -.929 & .544 & 2.915 & 1 & .088 & .40 & .14 & 1.15 \\
\hline \multicolumn{1}{|c|}{ Both } & -1.368 & .488 & 7.852 & 1 & .005 & .26 & .10 & .66 \\
\hline Ban on smoking & .421 & .207 & 4.148 & 1 & .042 & 1.52 & 1.02 & 2.28 \\
\hline Coping Pros & .041 & .025 & 2.851 & 1 & .091 & 1.04 & .99 & 1.09 \\
\hline Temptations & -.126 & .028 & 20.266 & 1 & .001 & .88 & .84 & .93 \\
\hline Stage stress mgmt. & .134 & .123 & 1.178 & 1 & .278 & 1.14 & .90 & 1.46 \\
\hline Gender & .042 & .422 & .010 & 1 & .922 & 1.04 & .46 & 2.38 \\
\hline Constant & 10.27 & 4.254 & 5.837 & 1 & .016 & & & \\
\hline
\end{tabular}

* Italicized variables attained significance at $\mathrm{p}<.05$

The strength of each predictor was evaluated through the Wald tests and the likelihood ratio tests. Based on these criteria, gender, GPA, number of smoking friends and stages of stress management were excluded from further models. In one intermediate model the coping pros variable was also excluded from the final model, since it failed to reach significance and did not significantly improve the fit of the model. The final main effects model had four predictors: age, parents' smoking, attitudes towards smoking bans and temptations (see Table 2). 
Table 2

Final logistic regression model for smokers/exsmokers*

\begin{tabular}{|l|r|r|r|r|r|r|r|r|}
\hline & \multicolumn{1}{|c|}{ B } & \multicolumn{1}{|c|}{ S.E. } & \multicolumn{1}{c|}{ Wald } & df & \multicolumn{1}{c|}{ Sig. } & \multicolumn{1}{c|}{ OR } & \multicolumn{2}{c|}{ 95.0\% C.I. for OR } \\
\hline & & & & & & & \multicolumn{1}{c|}{ Lower } & \multicolumn{1}{c|}{ Upper } \\
\hline Age & -.420 & .177 & 5.607 & 1 & .018 & .66 & .46 & .93 \\
\hline Parents' smoking & & & & & & & & \\
\hline No (Reference) & & & 10.791 & 3 & .013 & & & \\
\hline Only father & -.667 & .545 & 1.494 & 1 & .222 & .51 & .18 & 1.50 \\
\hline Only mother & -1.037 & .514 & 4.063 & 1 & .044 & .36 & .13 & .97 \\
\hline Both & -1.533 & .478 & 10.292 & 1 & .001 & .22 & .09 & .55 \\
\hline Ban on smoking & .479 & .182 & 6.894 & 1 & .009 & 1.61 & 1.13 & 2.31 \\
\hline Temptations & -.105 & .021 & 24.569 & 1 & .001 & .90 & .86 & .93 \\
\hline Constant & 10.374 & 3.322 & 9.753 & 1 & .002 & & & \\
\hline
\end{tabular}

* Italicized variables attained significance at $\mathrm{p}<.05$

At the next step four potential two-way interactions were examined, but none reached significance and none was included in the model. The four predictors model demonstrated a good fit as indicated by the omnibus chisquare test, $\chi^{2}(6)=63.70, p<.05$, and the Hosmer Lemeshow test, $\chi^{2}(8)=13.06, \mathrm{p}>.05$.

The model was used to create a classification rule with equal prior probabilities for the two groups. The discriminatory power of the model indicated by the area under the ROC curve was very good with a value of .823 . The correct classification rate for the pre-action (smoker) group was $94.3 \%$ and for the postaction (exsmoker) group $39.6 \%$ leading to an overall correct classification rate of $82.3 \%$. The chance classification rate with equal prior probabilities was $50 \%$ for both groups, so it can be concluded that despite the rather good overall correct classification rate the model had rather low sensitivity.

\section{Logistic Regression: Risk for Smoking Initiation}

The model building strategy for smoking initiation followed the same steps. The variables included in the multivariate logistic regression model were selected through a series of univariate tests with smoking risk status (defined as preaction (higher risk) vs. postaction (lower risk) on the prevention staging algorithm) as the outcome variable. A liberal $\mathrm{p}$ value of .20 was used to select variables for inclusion in the model. Based on this criterion the following variables were selected for the multivariate analysis: smoking status of siblings and parents, smoking allowed in the house, possession of brand logo item, plans for the future, attitudes towards smoking policy, difficulty of quitting, and beliefs about the relationship between smoking and weight. In addition, all TTM constructs (temptations, pros, cons and stages of effective stress management) reached significance and were included in the logistic regression model. The correlations among these variables were examined in order to test for potential collinearity. Parent's smoking status and house rules on smoking had a high negative correlation (-.566) and only the variable with the higher t-score (home smoking) was retained for the multivariate analysis.

The results of the logistic regression model containing all selected variables are presented in Table 3. 
Table 3

Initial logistic regression model for nonsmokers (higher/lower risk of initiation)*

\begin{tabular}{|l|r|r|r|r|r|r|r|r|}
\hline & \multicolumn{1}{|c|}{ B } & \multicolumn{1}{c|}{ S.E. } & \multicolumn{1}{c|}{ Wald } & \multicolumn{1}{c|}{ df } & \multicolumn{1}{c|}{ P } & \multicolumn{1}{|c|}{ OR } & \multicolumn{2}{|c|}{ 95.0\% C.I. for OR } \\
\hline & & & & & & & \multicolumn{1}{c|}{ Lower } & \multicolumn{1}{c|}{ Upper } \\
\hline Smoking of siblings & & & & & & & & \\
\hline \multicolumn{1}{|c|}{ Nonsmokers (Ref) } & & & 2.464 & 2 & .292 & & & \\
\hline \multicolumn{1}{|c|}{ No siblings } & .106 & .414 & .066 & 1 & .798 & 1.11 & .49 & 2.50 \\
\hline \multicolumn{1}{|c|}{ Smokers } & .597 & .382 & 2.437 & 1 & .119 & 1.82 & .86 & 3.85 \\
\hline \# of smoking friends & .164 & .173 & .898 & 1 & .343 & 1.18 & .84 & 1.65 \\
\hline Smoking allowed in house & .008 & .316 & .001 & 1 & .979 & 1.01 & .54 & 1.87 \\
\hline Plans for the future & .175 & .117 & 2.235 & 1 & .135 & 1.19 & .95 & 1.50 \\
\hline Promotional item & -.219 & .218 & 1.011 & 1 & .315 & .80 & .52 & 1.23 \\
\hline Offered free cigarette & -.565 & .675 & .701 & 1 & .403 & .57 & .15 & 2.13 \\
\hline Smoking harmful & -1.108 & .477 & 5.401 & 1 & .020 & .33 & .13 & .84 \\
\hline Hard to quit & -.280 & .167 & 2.790 & 1 & .095 & .76 & .54 & 1.05 \\
\hline Ban on smoking & -.381 & .185 & 4.219 & 1 & .040 & .68 & .48 & .98 \\
\hline Pros & -.045 & .017 & 6.865 & 1 & .009 & .96 & .92 & .99 \\
\hline Cons & .031 & .018 & 2.818 & 1 & .093 & 1.03 & .99 & 1.07 \\
\hline Temptations & .050 & .017 & 8.519 & 1 & .004 & 1.05 & 1.02 & 1.09 \\
\hline Stages Stress Mgmt. & -.159 & .096 & 2.726 & 1 & .099 & .85 & .71 & 1.03 \\
\hline Constant & 4.511 & 2.485 & 3.294 & 1 & .070 & 90.97 & & \\
\hline
\end{tabular}

* Italicized variables attained significance at $\mathrm{p}<.05$

The categorical variables included in the model were dummy coded. The reference groups were participants for whom smoking was not allowed in the house, were not offered a cigarette by a representative and had a non-smoking sibling. The importance of each variable was examined through the Wald statistic (with $p<.01$ ) and through comparisons with univariate models. Based on these criteria the pros, cons, temptations, stages of stress, attitudes towards smoking policy, belief that smoking is hard to quit, and belief that smoking is harmful to health were retained in the model. The predictors in this intermediate model were examined and the cons, stages of stress management and the item on smoking being hard to quit were excluded, since they failed to reach significance and did not improve the fit of the model.

The results of the model with the remaining variables (pros, temptations, bans on smoking and smoking is harmful) demonstrated that all of the included variables were significantly related to the outcome. The coefficients from this reduced model were compared to the coefficients from the full model to check for any marked changes as a potential indicator that an important variable has been omitted. None of the coefficients demonstrated unexpectedly large change, so the analysis proceeded with a refinement of the main effects model. For this purpose the linearity in the logit of the continuous variables was tested using the design variables approach described by Hosmer and Lemeshow (2000). The method uses design categorical variables (determined through the quartiles of the distribution), which are fitted into a model and the resulting estimated coefficients are plotted against the midpoints of the groups. The results suggested that pros, temptations and belief that smoking should be banned in public places are linear. During this analysis, it was discovered that the variable assessing belief in the harms of smoking to health had a zero cell count in the contingency table (no participants in the postaction stage disagreed with the statement). Since this is a numeric problem, which might distort final estimates the variable was transformed into a binary format (agree vs. definitely agree) and the regression analysis was repeated. The results of this analysis are presented in Table 4. 
Table 4

Final model for nonsmokers (higher/lower risk of initiation)*

\begin{tabular}{|l|r|r|r|r|r|r|r|r|}
\hline & \multicolumn{1}{|c|}{ B } & \multicolumn{1}{c|}{ S.E. } & \multicolumn{1}{c|}{ Wald } & df & \multicolumn{1}{l|}{ Sig. } & \multicolumn{1}{c|}{ OR } & \multicolumn{2}{|c|}{ 95.0\% C.I. for OR } \\
\hline & & & & & & & Lower & \multicolumn{1}{c|}{ Upper } \\
\hline Smoking harmful ${ }^{1}$ & -1.204 & .472 & 6.499 & 1 & .011 & .30 & .12 & .76 \\
\hline Temptations & .068 & .015 & 19.777 & 1 & .001 & 1.07 & 1.04 & 1.10 \\
\hline Pros & -.051 & .015 & 10.754 & 1 & .001 & .95 & .92 & .98 \\
\hline Ban on smoking & -.475 & .167 & 8.056 & 1 & .005 & .62 & .45 & .86 \\
\hline Constant & 1.153 & 1.095 & 1.109 & 1 & .292 & 3.16 & & \\
\hline
\end{tabular}

$*$ Italicized variables attained significance at $\mathrm{p}<.05 ;{ }^{1}$ Binary coded

As can be seen the coefficients did not differ significantly from the model before the recoding and the model was retained as a final main effects model. At the next step, tests for potential interactions were performed. All possible two-way interactions were examined, but none was significant and hence none was included in the model.

The final step was assessment of the goodness of fit of the final model. Both the Hosmer and Lemeshow test $\left(\chi^{2}(8)=12.59, p>.05\right)$ and the omnibus chi-square test $\left(\chi^{2}(4)=76.58, p<.05\right)$ indicated a good fit of the model. The area under the ROC curve was .795, which is indicative of good discrimination (Hosmer \& Lemeshow, 2002). A classification rule with equal prior probabilities was used in the analysis. The overall rate of correct classification was $72.7 \%$, with $84.1 \%$ of the low risk group/postaction group and $55.4 \%$ of the high-risk group correctly classified. These results indicate high specificity, but low sensitivity of the model.

The final model indicated that consistent with TTM predictions, people who had higher scores on the Pros of staying smoke-free had a lower probability of being in the elevated risk group with all other factors being equal. A one point difference in the T-scores of the Pros scale was associated with a change in the odds ratio of .95 . Also as anticipated higher scores on the Temptation to try smoking scale were associated with a higher probability of being at risk for smoking initiation. A one point increase in Temptations $\mathrm{T}$-score increased the risk of being in the higher-risk group by $7 \%$. High scores on both of the other two predictors were associated with a lower probability of being at risk. The belief that smoking is harmful to health was a stronger predictor of being in the lower risk group (OR .300) than attitudes towards smoking policy (OR .620).

\section{Discussion}

In this relatively large sample of Bulgarian school students, a series of logistic regressions revealed the most important factors differentiating current and former smokers: less support for smoking bans in public areas, parental smoking status (especially mothers), older age and higher Temptations to smoke were associated with increased odds of being a smoker. Also noteworthy was that several variables associated with smoking cessation in other cultures and research were not associated with it here. Specifically, gender, plans for the future, stress levels and stress management, Pros and Cons of smoking, and peer smoking did not add predictive value to this model.

Similarly, in Bulgarian adolescent nonsmokers, a series of logistic regressions revealed that the most important factors differentiating those at higher risk for smoking initiation from those at lower risk were: the belief that smoking is not that harmful, less support for smoking bans in public places, higher Temptations to try smoking and lower Pros of being smoke-free. The finding that the belief that smoking is less harmful to health was a factor associated with elevated risk for smoking initiation supports increased efforts to communicate the harmful effects of smoking more clearly as part of prevention programs. 
There were only two variables that were strongly associated with both outcome variables: Temptations to smoke and Temptations to try smoking differentiated between smokers/exsmokers and higher risk/lower risk nonsmokers respectively. These data support TTM conceptualizations of self efficacy and temptations for smoking as relevant for both smoking cessation and prevention. Support for smoking bans in public places, with ex-smokers and lower-risk nonsmokers predictably expressing more favorable attitudes was also associated with lower risk in both models. Unfortunately, this variable was measured here using a single item, resulting in low reliability. Its strong association with smoking behavior, however, warrants further research and development of better measures. In addition, in light of some recent results suggesting low awareness of the health risks associated with smoking in Bulgaria (Dokova, Stoeva, Kirov, Feschieva, Petrova, Powles, 2005) increased focus on health education regarding the risks of smoking is warranted.

The most unexpected finding was that contrary to our expectations and the abundant literature the factors of stress and peer smoking were not strongly associated with smoking cessation or increased risk of smoking initiation. It is possible that this result was due to low sensitivity of these measures in this population, but only future studies can clarify this issue further.

The results presented here should be interpreted with some caution due to the limitations of the study. The differences in the psychometric properties of the included measures, with some constructs assessed through single items and others through full scales, is a weakness. Most importantly, the cross-sectional nature of the study prohibits any predictive causal statements. Future studies with better measures and more sophisticated longitudinal designs are needed to determine the direction of these relationships.

Despite these limitations and due to the fact that comparable studies on predictors of smoking behavior in Bulgaria are extremely rare, this study helps to fill the gap in the existing literature on factors associated with smoking behavior among Bulgarian adolescents. Better understanding of these factors can lead to the development of effective public health programs, which may in the long run help to close the East-West divide in public health. In addition, the study supports the applicability of TTM constructs within this Bulgarian sample, although more work on the Pros and Cons scales may add to their sensitivity in this population. Overall the results suggest that effective intervention programs to help parents quit smoking and/or to help adolescents to avoid temptations to smoke may have a positive influence on tobacco control in Bulgaria. Future research should continue to explore the theoretically and empirically informed multivariate influences on smoking behavior worldwide in an effort to develop more effective smoking prevention and cessation programs for adolescents.

\section{References}

Anatchkova, M. D., Redding, C. A., Rossi, J. L. (2006). Development and validation of measures for decisional balance and self-efficacy for Bulgarian adolescent smokers. Addictive Behaviors, 31, 155-61.

Anatchkova, M. D., Redding, C. A., Rossi, J. L. (in press). Development and validation of measures for decisional balance and self-efficacy for Bulgarian adolescent non-smokers. Substance Use and Misuse.

Anguelov, A., Petkova, E., \& Lazarov, P. (1999). Promoting health educational programmes for the prevention of tobacco, alcohol and drug abuse in the school environment. Drugs: Education, Prevention and Policy, 6, 332-335.

Balabanova, D., Bobak, M., \& McKee, M. (1998). Patterns of smoking in Bulgaria. Tobacco Control, 7 , 383-385. 
Cohen, S., Kamarck, T., Mermelstein, R. (1983). A global measure of perceived stress. Journal of Health and Social Behavior, 24, 385-396.

Coogan, P. F., Adams, M., Geller, A. C., Brooks, D., Miller, D. R., Lew, R. A., \& Koh, H. K. (1998). Factors associated with smoking among children and adolescents in Connecticut. American Journal of Preventive Medicine, 15, 17 - 24.

Corrao M. A., Guindon, G. E., Sharma, N., \& Shokoohi, D. F. (Eds) (2000). Tobacco control country profiles. Atlanta, GA: American Cancer Society.

Dokova, K., Stoeva, K., Kirov, P., Feschieva, N., Petrova, S., Powles, J. (2005). Public understanding of the causes of high stroke risk in northeastern Bulagria. European Journal of Public Health, 15, 313-316.

Fava, J. L., Ruggiero, L., \& Grimley, D. M. (1998). The development and structural confirmation of the Rhode Island Stress and Coping Inventory, Journal of Behavioral Medicine, 21, 601-611.

Fiore, M. C. (1992). Trends in cigarette smoking in the United States: the epidemiology of tobacco use. The Medical Clinics of North America, 76, 289-303.

Ginter, E. (1997). Cardiovascular disease prevention in Eastern Europe. Nutrition, 14, 452 - 457.

Glendinning, A., \& Inglis, D. (1999). Smoking behavior in youth: the problem of low self-esteem. Journal of Adolescence, 22, 673-682.

Griesler, P. C., \& Kandel, D. B. (1998). Ethnic differences in correlates of adolescent cigarette smoking. Journal of Adolescent Health, 23, 167-180.

Hosmer, D. W., \& Lemeshow, S. (2000). Applied logistic regression. (2nd ed.). New York: John Wiley and Sons, Inc.

Jackson, C., \& Henricksen, L. (1997) Do as I say: Parent smoking, antismoking socialization, and smoking onset among children. Addictive Behaviors, 1, 107-114.

Jackson, C. (1997). Initial and experimental stages of tobacco and alcohol use during late childhood: relation to peer, parent and personal risk factors. Addictive Behaviors, 23, 685-698.

Kawabata, T., Shimai, S., Nishioka, N. (1998). The relationship between smoking behavior and selfesteem among elementary and junior high school students. Japanese Journal of Public Health, 45, 15-26. (Abstract).

Kotarov, G. (2002). Promeni v povedenieto na deca I roditeli posredstvom hudojestveni deinosti: Mejdunaroden Konkurs za destka risunka "Ne na cigarite". Soicalna medicina, 3.

Koval, J. J., Pederson, L. L., Mills, C. A., McGrady, G. A., \& Carvajal, S. C. (2000). Models of the relationship of stress, depression, and other psychosocial factors to smoking behavior: A comparison of a cohort of students in grades 6 and 8. Adolescence, 35, 259-270.

Mauriello, L. M., Rossi, J. S., Fava, J., Redding, C. A., Robbins, M., Meier, K. S., \& Prochaska, J. O. (2006). Assessment of the pros and cons of stress management among adolescents: Development and validation of a decisional balance measure. Manuscript submitted for publication.

McCubbin, H. I., Needle, R. H., \& Wilson, M. (1985). Adolescent health risk behaviors: Family stress and adolescent coping as critical factors. Family Relations: Journal of Applied Family \& Child Studies.Special Issue: The Family and Health Care, 34, 51-62.

Ministry of Health (2002). Nacionalna programa za ogranichavane na tiutiunopusheneto 2002-2005.

Najem, G. R., Batuman, F., Smith, A. M., \& Feuerman, M. (1997). Patterns of smoking among inner-city teenagers: smoking has a pediatric age of onset. Journal of Adolescents Health, 20, $226-231$.

Pallonen, U. E., Prochaska, J. O., Velicer, W. F., Prokhorov, A. V., \& Smith, N. F. (1998). Stages of acquisition and cessation for adolescent smoking: An empirical integration. Addictive Behaviors. 23, 303-324.

Pederson, L. L., Koval, J. J., McGrady, G. A., \& Tyas, S. L (1998). The degree and type of relationship between psychosocial variables and smoking status for students in grade 8: Is there a doseresponse relationship? Preventive Medicine, 27, 337-347.

Piko, B. F., \& Fitzpatrick, K. M. (2002). Without protection: substance use among Hungarian adolescents in high-risk settings. The Journal of Adolescent Health, 30, 463-466. 
Plummer, B. A., Velicer, W. F., Redding, C. A., Prochaska, J. O., Rossi, J. S., Pallonen, U. E. et al. (2001). Stage of change, decisional balance, and temptations for smoking: measurement and validation in a large, school-based population of adolescents. Addictive Behaviors, 26, 551-571.

Proescholdbell, R. J., Chassin, L., \& MacKinnon, D. P. (2000). Home smoking and adolescent smoking. Nicotine and Tobacco Research, 2, 159-167.

Prochaska, J. O., \& DiClemente, C. C. (1983). Stages and processes of self-help smoking: toward an integrative model of change. Journal of Consulting Psychology, 51, 390-395.

Redding, C. A., Rossi, J. S, Pallonen, U. E., Prochaska, J. O., Abrams, D. B., Velicer, W. F., Meier, K., Greene, G. W., \& Rossi, S. R. (1998). Measures of family influence on healthy behavior changes. Annals of Behavioral Medicine, 20, S215 (Abstract).

Redding, C. A., Rossi, J. S, Pallonen, U. E., Prochaska, J. O., Abrams, D. B., Velicer, W. F., Plummer, B., Meier, K., Greene, G. W., \& Rossi, S. R. (1999). Measures of family influence on healthy behavior changes in parents of adolescents. Annals of Behavioral Medicine, 21, S174 (Abstract).

Siqueira, L., Diab, M., Bodian, C., Rolnitzky, L. (2000). Adolescents becoming smokers: the roles of stress and coping methods. Journal of Adolescent Health, 27, 399-408.

Tabachnik, B. G., \& Fidell, L. S. (2001). Using multivariate statistics (4th ed.). Boston: Allyn \& Bacon.

Tulevski, B \& Vasilevski, N. (2000). Short-term results from the smoking cessation campaign "quit and win 2000" in Bulgaria. Socialna Medicina, 4.

Uitenbroek, D. G., Kerekovska, A., \& Festchieva, N. (1996). Health lifestyle behavior and sociodemographic characteristics. A study of Varna, Glasgow and Edinburgh. Social Science Medicine, 43, 367-377.

Unger, J. B., Cruz, T. B., Schuster, D., Flora, J., \& Johnson, C. A. (2001). Measuring exposure to pro and anti-tobacco marketing among adolescents: Intercorrelations among measures and associations with smoking status. Journal of Health Communication, 6, 11-29.

Urberg, K. A., Cheng, C. H., \& Shyu, S. J. (1991). Grade changes in peer influence on adolescent cigarette smoking: A comparison of two measures. Addictive Behaviors, 16, 21-28.

US Surgeon General. (1994). Preventing tobacco use among young people: A Report of the Surgeon General 1994. Atlanta, GA: US Department of Health and Human Services. Retrieved June 1, 2006, from http://www.cdc.gov/tobacco/sgr/sgr 1994/index.htm

US Surgeon General. (2000). Reducing tobacco use: A report of the surgeon general - executive summary. Nicotine and Tobacco Research, 2, 379-395.

Vollrath, M. (1998). Smoking, coping and health behavior among university students. Psychology \& Health, 13, 431-443.

Wang, M. Q., Fitzhugh, E. C., Westerfield, R. C.,\& Eddy, J. M. (1995). Family and peer influence on smoking behavior among adolescents: an age trend. Journal of Adolescents Health, 16, 200-203.

Weinrich, S., Hardin, S., Valois, R. F., \& Gleaton, J. (1996). Psychological correlates of adolescent smoking in response to stress. American Journal of Health Behavior, 20, 52-60.

Wills, T. A. (1986). Stress and coping in early adolescence: Relationships to substance use in urban school samples. Health Psychology, 5, 503-529.

World Health Organization. (1997). Tobacco or Health: A global status report. Retrieved June 1, 2006, from http://www.cdc.gov/tobacco/who/bulgaria.htm

\section{Acknowledgements}

This research was partially supported by a Jacobs Foundation Dissertation Grant awarded to the first author. The work presented here is part of a dissertation project supervised by the second and third authors. Portions of these data were presented at the International Meeting of the Society of Behavioral Medicine, Germany, 2004. Authors wish to acknowledge the cooperation of the Bulgarian Ministry of Education, as well as the many principals, teachers and students who participated in this study. 
Author Information

Milena D. Anatchkova, Ph.D.*

QualityMetric Inc.

640 George Washington Ave.

Lincoln, RI 02865-4207

Ph.: 401-334-8800 Ext. 244

Fax.: 401-334-8801

E-Mail: manatchkova@qualitymetric.com

Colleen A. Redding

Joseph S. Rossi

University of Rhode Island

Cancer Prevention Research Center

* corresponding author 